\title{
An evaluation of the sustainability of the Olympic Games
}

\author{
Martin Müller®1凶, Sven Daniel Wolfe', Christopher Gaffney², David Gogishvili', Miriam Hug ${ }^{3}$ and \\ Annick Leick ${ }^{1}$
}

\begin{abstract}
The Olympic Games claim to be exemplars of sustainability, aiming to inspire sustainable futures around the world. Yet no systematic evaluation of their sustainability exists. We develop and apply a model with nine indicators to evaluate the sustainability of the 16 editions of the Summer and Winter Olympic Games between 1992 and 2020, representing a total cost of more than US\$70 billion. Our model shows that the overall sustainability of the Olympic Games is medium and that it has declined over time. Salt Lake City 2002 was the most sustainable Olympic Games in this period, whereas Sochi 2014 and Rio de Janeiro 2016 were the least sustainable. No Olympics, however, score in the top category of our model. Three actions should make Olympic hosting more sustainable: first, greatly reducing the size of the event; second, rotating the Olympics among the same cities; third, enforcing independent sustainability standards.
\end{abstract}

T he Olympic Games are the most watched and the most expensive events on Earth. Half the world's population is expected to see coverage of the Tokyo Olympics, when and if they take place in summer $2021^{1}$. This Summer Olympics will have triggered expenditures of between US $\$ 12$ billion and US $\$ 28$ billion (ref. ${ }^{2}$ ), depending on how one counts. These amounts are not atypical for a Summer Olympic Games. ${ }^{3}$. They make the event one of the most expensive serial human interventions in the world ${ }^{4}$. Their high political priority, and the global attention they attract, give the Olympic Games the potential to alter decision-making at the national and even international levels and to reach people around the world.

The large expenditure and exceptional political leverage of the Olympic Games present a chance to pioneer necessary sustainability transformations $s^{5}$ well beyond the trillion-dollar event industry ${ }^{6}$. Predominantly an urban mega-project ${ }^{7,8}$, the Olympic Games could prove particularly useful in addressing the looming sustainability challenges for cities in an age of rapid urbanization: reducing greenhouse gas emissions, guaranteeing social peace and justice, providing sustainable mobility and curbing urban sprawl ${ }^{9,10}$. Together with their exceptional visibility, the Olympic Games provide a unique platform to reach a global audience and could serve as a model for cities, countries and other events around the world to emulate.

Academic opinion, however, is divided regarding the sustainability of mega-events such as the Olympic Games. While some scholars doubt whether mega-events can ever be sustainable, others extol their virtues. The former group criticizes mega-events as paying mere lip service to sustainability while pursuing a business model that plays to elite interests, global consumption and transnational investment flows ${ }^{11-15}$. The latter group, by contrast, considers mega-events as windows of opportunity to push and showcase innovative solutions to global challenges and as political levers for moving towards sustainable practices of living and consumption ${ }^{16-19}$.

That the Olympics be sustainable is a requirement laid down in the contract between Olympic host cities and the International Olympic Committee (IOC). Sustainability is one of the three pillars of the IOC's road map for the future, Olympic Agenda 2020, and features prominently in its continuation, Olympic Agenda $2020+5^{20}$. The IOC's sustainability strategy aims to "ensure the Olympic Games are at the forefront in the field of sustainability" ${ }^{21}$. In 2018, the United Nations passed a resolution that declared "sport as an enabler of sustainable development" ${ }^{22}$ and signed a letter of intent highlighting the contribution of the Olympic Games to the UN Sustainable Development Goals (SDGs) ${ }^{23}$. Nonetheless, there is a notable absence of systematic studies that interrogate such claims. The IOC made an effort in the early 2000s to set up a coherent measurement of the impacts of the Olympic Games in each host city over a period of more than ten years, in an attempt to foreground sustainability objectives ${ }^{24}$. Only the Winter Olympics in Vancouver in 2010, however, completed the full cycle of this so-called Olympic Games Impact study, and it was subsequently abandoned in 2017. The few independent attempts to evaluate the sustainability of the Olympic Games, and of mega-events more generally, are limited to one edition of the event and operate with incommensurable models that make longitudinal comparisons impossible.

Against this background, this contribution evaluates the sustainability of the Olympic Games in a systematic longitudinal study. It analyses the 16 editions of the Summer and Winter Olympic Games from Albertville 1992 to Tokyo $2020(N=16)\left(\right.$ ref. $\left.{ }^{25}\right)$. This sample represents total sports-related costs of more than US $\$ 70$ billion, not counting the cost of ancillary infrastructure, which is often multiple times higher ${ }^{3}$. It represents an important advance both for sustainability scholarship and for sustainability policy. For scholars, it offers a model for conceptualizing and empirically evaluating the often diverging claims regarding the sustainability of humankind's largest and most expensive event. For decision makers, it provides empirical data for policy outcomes ${ }^{26}$, answering the question to what degree hosting the Olympics can or cannot contribute to sustainability goals.

\section{Results}

Sustainability remains an elusive concept in the Olympic Games, and in mega-events more generally. Every Olympic Games now

'Department of Geography and Sustainability, University of Lausanne, Lausanne, Switzerland. ${ }^{2}$ Tisch Center for Hospitality, New York University, New York City, NY, USA. ${ }^{3}$ Department of Geography, University of Bern, Bern, Switzerland. $\bigotimes_{e}$-mail: martin@martin-muller.net 


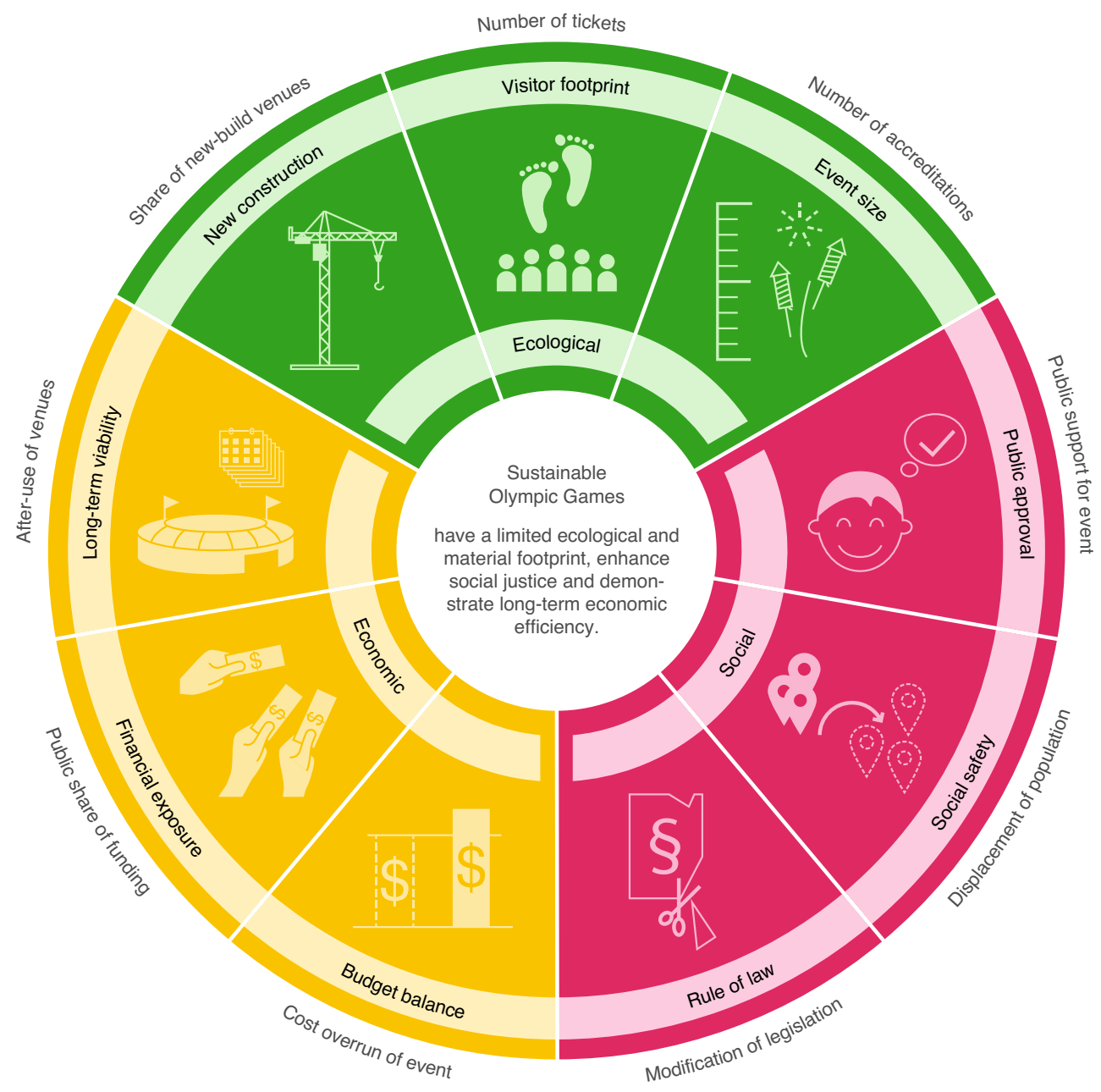

Fig. 1 | Definition and conceptual model of sustainability in the Olympic Games. The definition and model assign equal weight to the classic three dimensions of sustainability (inner ring-ecological, social and economic), evaluating them with three indicators each (outer ring).

claims to be sustainable, but all equally fail to provide a coherent definition or model for independent evaluation ${ }^{24,27,28}$.

Definition and model. Filling this lacuna, we first develop a definition and conceptual model of the sustainability of the Olympic Games, depicted in Fig. 1. We define 'sustainable Olympic Games' along three dimensions: having a limited ecological and material footprint, enhancing social justice and demonstrating economic efficiency. This definition reflects current debates on sustainability as minimizing resource use while guaranteeing minimum thresholds of social and economic well-being ${ }^{29}$. The model strikes a balance between strong conceptions of sustainability, which would put ecological limits over social and economic gains, and weak conceptions of sustainability, which would see the ecological, social and economic dimensions as mutually substitutable and have a stronger focus on social and economic development ${ }^{30}$. It ties into policy debates on sustainability such as the 17 United Nations SDGs, which envision just human development while decoupling resource consumption $^{31}$, and the Paris Agreement ${ }^{32}$.

The conceptual model further subdivides each of the three dimensions of sustainability into three indicators (indicated with icons in Fig. 1) that we measured for each Olympic Games from 1992 to 2020.

From this conceptual model, we develop a score card for measuring sustainability ${ }^{24}$. We score each of the nine indicators on a scale from 0 to 100 , where 0 means 'least sustainable' and 100 'most sustainable'. In assigning equal weight to each dimension, we correct for the predominant focus of existing studies on the economic impacts of events and on 'greening' (waste reduction, environmental impacts, eco-certification and so on), at the expense of the social dimension $^{27,33-35}$.

We then apply the model to all Olympic Games since 1992 $(N=16)$, on the basis of our database ${ }^{25}$. The year 1992 marks the beginning of a period of strong growth in the size of the Olympic Games $^{36}$, bringing challenges of sustainability to the fore. At the same time, ideas of sustainability started to gain more traction with the Earth Summit in Rio de Janeiro, and sustained attention to environmental issues in the Olympic Games started to emerge. Supplementary Table 1 provides full details of each indicator, and the Methods section explains the approach to constructing the model and the score card.

Overall sustainability. Overall results in Fig. 2a demonstrate that the sustainability of the Olympic Games from 1992 to 2020 is medium, at 48 out of 100 points possible. Mean scores for each of the three dimensions fall within a narrow range of 44 (ecological dimension) to 47 (economic dimension) and 51 (social dimension). Sustainability is therefore fairly consistent across the three dimensions.

There are, however, important differences between the scores of indicators. 'Budget balance' shows the lowest value $(M=26)$, underscoring the Olympics' consistent history of cost overrun ${ }^{3}$. 'New 
a

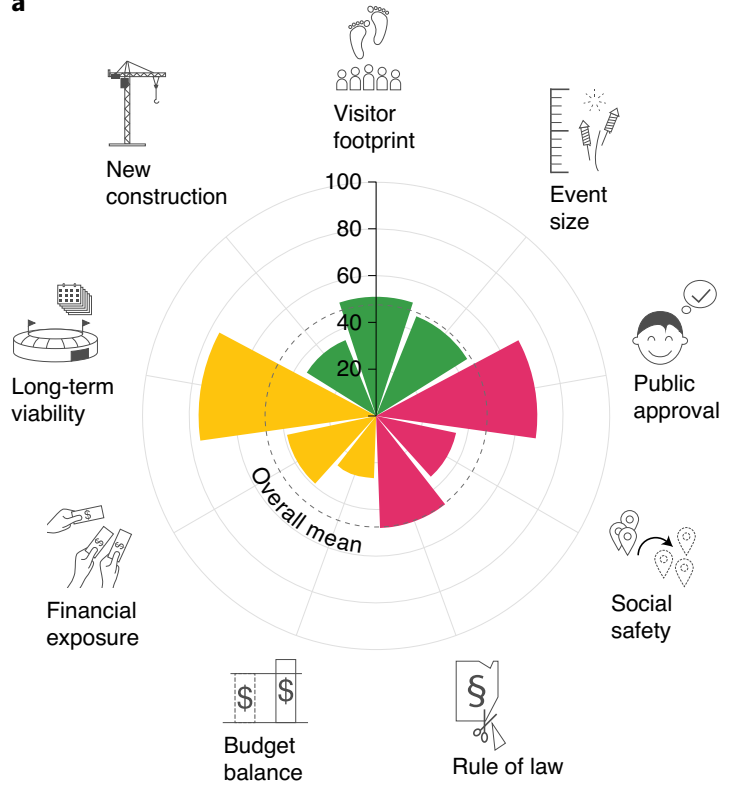

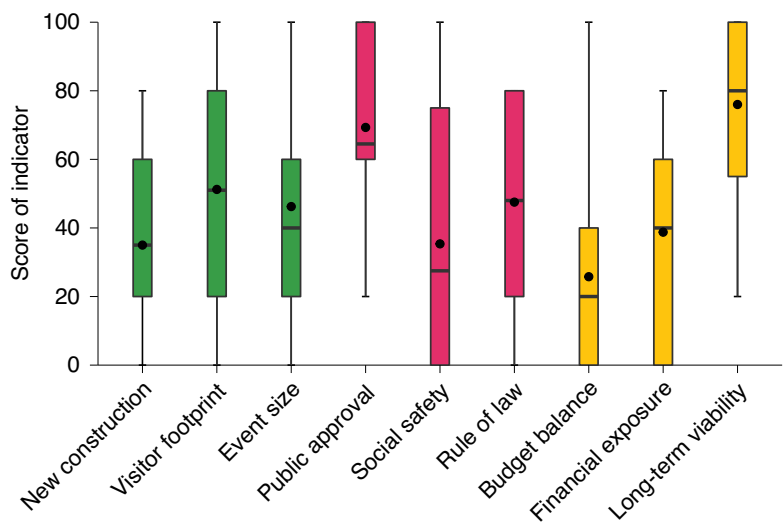

Fig. 2 | Overall sustainability of the Olympic Games 1992-2020 by indicator. a, Mean values of nine sustainability indicators. b, Distribution of values. Dots show the mean value; middle lines show the median; box limits show upper and lower quartiles; whiskers show maximum/minimum. See Supplementary Data for full descriptive statistics.

construction' and 'social safety' also receive poor ratings $(M=35$ for both), indicating that extensive construction of new sports venues and the displacement of people are regular occurrences in the preparation for an Olympic Games. By contrast, the Olympic Games have a relatively strong record in finding adequate after-use for the key sports and non-sports venues, as expressed in the indicator 'long-term viability' $(M=76)$. This finding suggests the need to revise the dominant opinion that the event leaves numerous so-called white elephants, that is, oversized and underused sports venues $^{37-39}$. On average, the Olympics in our sample also enjoy high public approval $(M=69)$.

The mean values disguise considerable variance in the scores of each indicator across the 16 Olympic Games in the sample (Fig. 2b). Scores range on the full scale from 0 to 100 for six out of the nine indicators. This means that there is little consistency in how individual Olympic Games score on the indicators, with both very high and very low scores present. The presence of very high values (between 80 and 100) on each of the indicators also suggests that, in general, it has been possible to obtain high scores, and it is therefore conceivable to have much higher overall sustainability scores than the middling ones in our sample.

Development over time. During the period covered in our sample, the IOC and Olympic organizers adopted global policies such as Agenda 21 and the SDGs and applied them to the Olympic Games $^{40}$. Our data show, however, that despite these measures, the sustainability of the Olympic Games has decreased over time $\left(r_{\text {overall }}=-0.59, P<0.05\right)$. This negative trend becomes evident from Fig. 3. It holds true for all but the economic dimension, with the ecological record declining the most $\left(r_{\text {ecological }}=-0.65, P<0.01 ; r_{\text {social }}=\right.$ $-0.56, P<0.05)$. The Winter Games in Vancouver in 2010 were the first to be proclaimed as sustainable Games ${ }^{41}$. Yet, the Olympics held before Vancouver 2010 were more sustainable than those from Vancouver onward: Olympic Games from 1992 to 2008 have a mean sustainability score of 53 points, whereas those since Vancouver 2010 stand at only 39 points-a statistically significant difference $(t(14)=-2.80, P=0.01)$. The promotion of the environment and sustainability to a pillar of the Olympic policy agenda, as illustrated in Fig. 3, has not been able to stop or reverse the decline of sustainability over time.

Differences between Winter and Summer Games. The Summer and Winter Olympic Games have similar overall sustainability $\left(M_{\text {Summer }}=45, M_{\text {Winter }}=51, t(14)=0.98, P=0.35\right)$. There are, however, strong divergences between the scores of individual indicators, as displayed in Fig. 4. The Winter Games have a significantly smaller visitor footprint $(t(14)=-2.65, P=0.02)$ than the Summer Games. The Winter Games have also grown much less than the Summer Games and displace fewer people, which is probably due to the smaller size of the required venues and urban infrastructure $(t(11)=-2.32, P=0.05$, marginally above the threshold for statistical significance). By contrast, the Summer Games have a significantly lower share of new venues $(t(14)=2.65, P=0.02)$. The specialized venues required for the Winter Games, such as ski jumps and bobsleigh tracks, might contribute to that result. The Summer Games also garner higher approval than the Winter Games $(t=2.15$, $P=0.05$, marginally above the threshold for statistical significance), perhaps because winter sports appeal to a smaller share of the population. All other differences are not statistically significant.

The sustainability record of the Winter Games fluctuates much more than that of the Summer Olympics $\left(\mathrm{SD}_{\text {Summer }}=8\right.$ versus $\mathrm{SD}_{\text {Winter }}=15$ ). The extremes of the overall scores of the Winter Games range from a high of 71 points (Salt Lake City 2002) to a low of 24 points (Sochi 2014), compared with the more moderate extremes of 56 points (Barcelona 1992) and 29 points (Rio de Janeiro 2016) for the Summer Games. These findings suggest that hosting the Winter Games is more likely to result in either significantly more or significantly less sustainable Olympic Games, compared with the mean.

Individual host cities. Sustainability varies considerably across the 16 host cities of the Olympic Games in the sample. Figure 5a divides the total scores for the 16 events into four intervals. While 7 out of the 16 Olympics in our sample fall into the yellow zone of the 


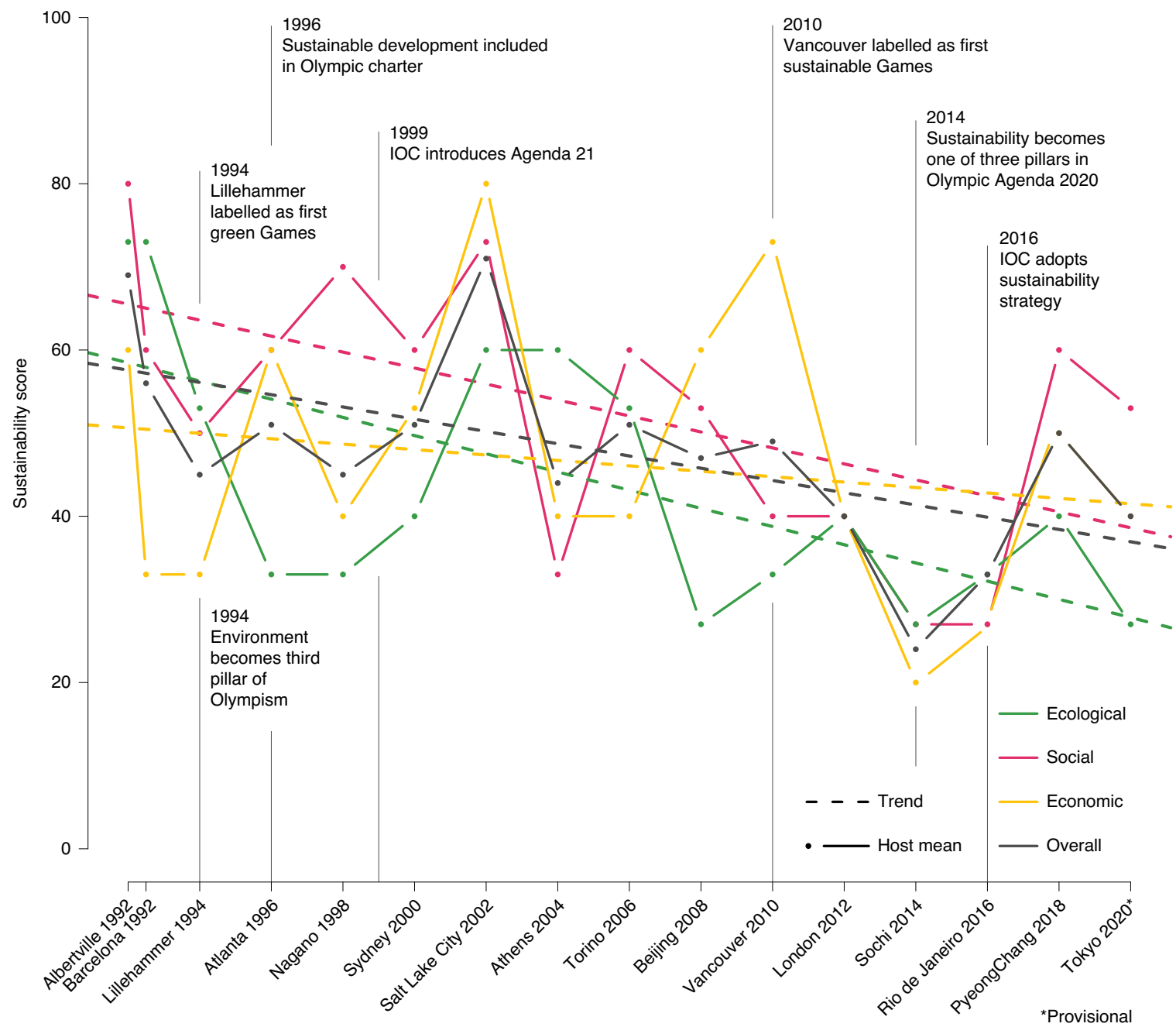

Fig. 3 | Trend lines and important milestones of sustainability in the Olympic Games, 1992-2020. Sustainability is decreasing overall and in its ecological and social dimensions. Dots indicate individual values of the Olympic Games; dashed lines indicate linear trends. All trend lines, except for the economic one, are significant at $P<0.05$.

second interval (often barely so, with just 50 or 51 points), eight fall into the problematic orange zone of the third interval and one falls into the red zone of the bottom interval. None manages to achieve a score in the top interval (75 to 100 points), what we call the green zone.

The most sustainable Olympics, all in the yellow zone, were held in Salt Lake City, United States, in $2002(M=71)$ and in Albertville, France, in $1992(M=69)$. Both were Winter Olympics. The Summer Olympics of Barcelona in 1992 are in third place, although with a considerably lower score $(M=56)$. Together with Albertville, they have the highest mean score in the ecological dimension among all cities in the sample.

That the gold and silver medals in sustainability go to Salt Lake City and Albertville is unexpected. Neither of the two cities is very prominent in the literature on sustainability in mega-events nor had they made far-reaching claims about sustainability. The Salt Lake City Olympics were overshadowed by a bribery scandal and the events of 11 September in the preceding year. The city aimed to use the Olympics primarily to improve its image and attract more tourists $^{42}$, but was not noted for its commitments to sustainability. In fact, it demonstrated a particular lack of attention to the social impacts of the event, according to some ${ }^{35}$. The Albertville 1992 Olympics, while taking environmental considerations into account, were severely criticized for the environmental damage caused by the construction of new sports venues ${ }^{43}$.

Our results urge a re-consideration of the experiences of Salt Lake City and Albertville for future Olympic Games. Salt Lake City scores highly because it has above-average scores across the board, although these are nowhere outstanding. Its economic performance is particularly remarkable and the best in the sample, with limited financial exposure, very good after-use of venues and a moderate cost overrun of $24 \%$. Albertville, by contrast, stands out for its performance in the ecological dimension. While it built many new venues, it was a small event with a moderate number of visitors and personnel, compared with other events in the sample, thus creating a comparatively limited ecological and material footprint.

At the tail end, the Winter Olympics in Sochi in 2014 and the Summer Olympics in Rio de Janeiro in 2016 feature the lowest sustainability scores. As our data show, the Olympics in Rio de Janeiro displaced a large number of residents for Olympics-related development and provided the occasion for the enactment of comprehensive legal exceptions. The resulting sports venues remained poorly used after the event, and cost overruns were the highest in the sample. Sochi is the only Olympics to fall into the bottom interval, or red zone. Next to extensive new construction and the high number of accredited participants, this is mostly due to its poor economic 

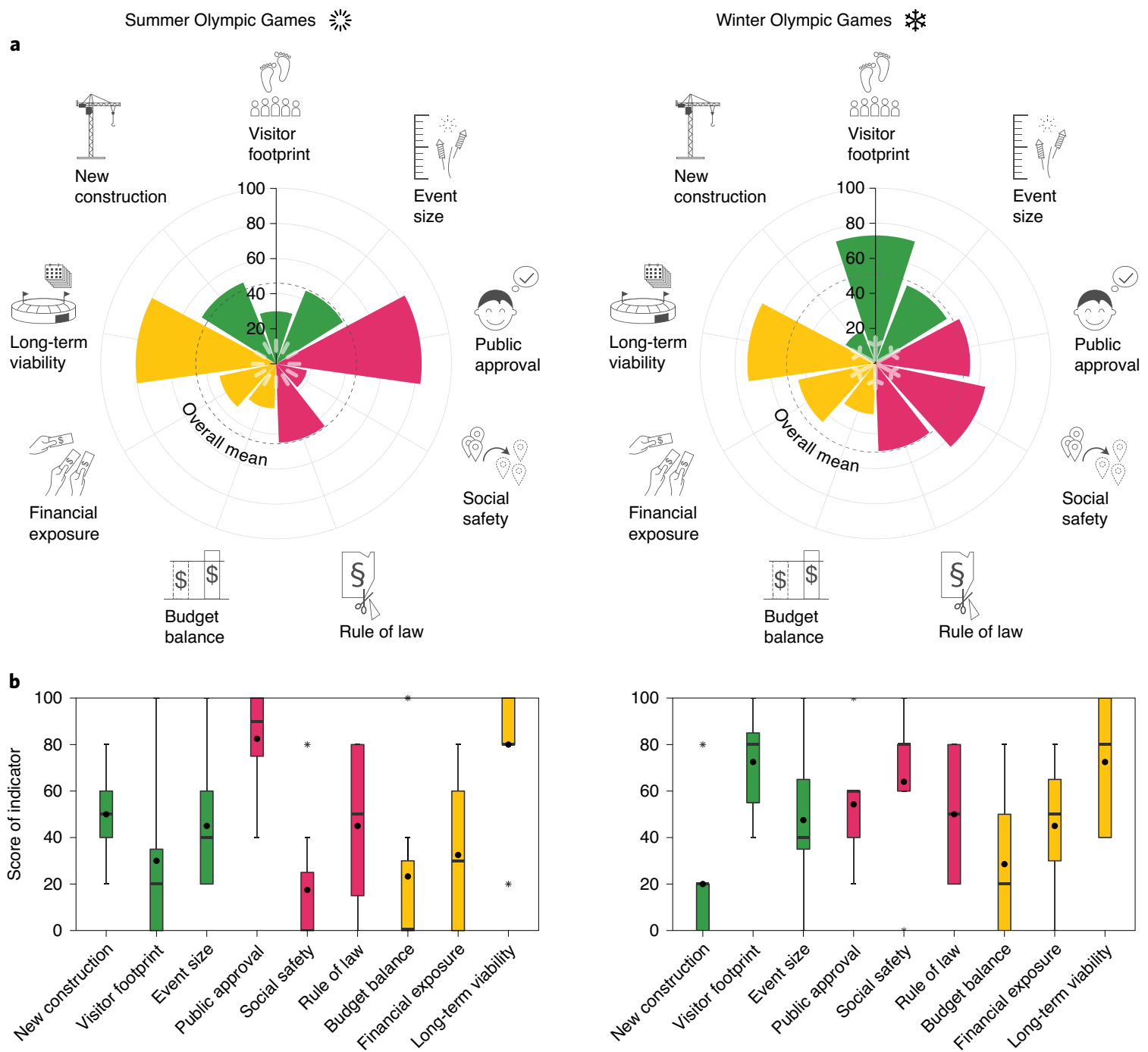

Fig. 4 | Sustainability of Summer and Winter Olympic Games compared, 1992-2020. a, Mean values of nine sustainability indicators. Summer and Winter Olympic Games have similar overall means but substantial divergences for individual indicators. b, Distribution of values. Dots show the mean value; middle lines show the median; box limits show upper and lower quartiles; whiskers show maximum/minimum; asterisks show outliers (1.5 times the interquartile range above the 75th percentile or below the 25th percentile). See Supplementary Data for full descriptive statistics.

performance: Sochi suffered the second-highest cost overruns in the sample, while not finding meaningful after-use for most venues.

Outlook for Tokyo 2020 Olympics. The majority of data for our model are already available for Tokyo 2020 (Fig. 5), to be held in 2021 , although some need to be seen as provisional (marked with * in Fig. 5) due to the uncertainty around this event as a consequence of COVID-19. Tokyo has substantial public financial exposure, with more than $50 \%$ of the sports-related cost footed by the state. While the Olympics have not much interfered with the rule of law, they have displaced more than 500 people. By contrast, new-venue construction is below average, with about $20 \%$ of venues being new venues. Figures for the number of visitors and accreditations are provisional at this time and based on organizers' forecasts. Overall, these Olympic Games score in the orange zone, at 40 points, below the long-time average of 48 points.

\section{Discussion}

The stakeholders of the Olympic Games paint them as paragons of sustainability. Our analysis reveals that this is not the case. The
Olympic Games between 1992 and 2020 have a medium sustainability level. Salt Lake City 2002 and Albertville 1992 have the best records but did not achieve high sustainability overall. There are no Olympics that score highly in all or even the majority of the indicators of our model. Cities such as Vancouver and London, which have marketed themselves as models of sustainable Olympic Games and have advised other Olympic hosts on sustainability, score below average $^{11,44,45}$. This result suggests that sustainability rhetoric does not match actual sustainability outcomes.

Sustainability in the Olympics has also significantly declined over time. Some recent Olympic Games have very poor sustainability, such as the Winter Games of 2014 in Sochi and the Summer Games of 2016 in Rio de Janeiro. This is despite the much-advertised priority of organizing sustainable Games since at least the 2010s. The power of the Olympic spectacle is not currently harnessed to transform unsustainable modes of global economic production, but to entrench them. This falls short of the humanist ideals of the Olympics to be a force for progress and improvement-for humanity and for the planet.

However, our analysis shows that organizing more sustainable Olympic Games is possible. There are Olympic Games in our 
a

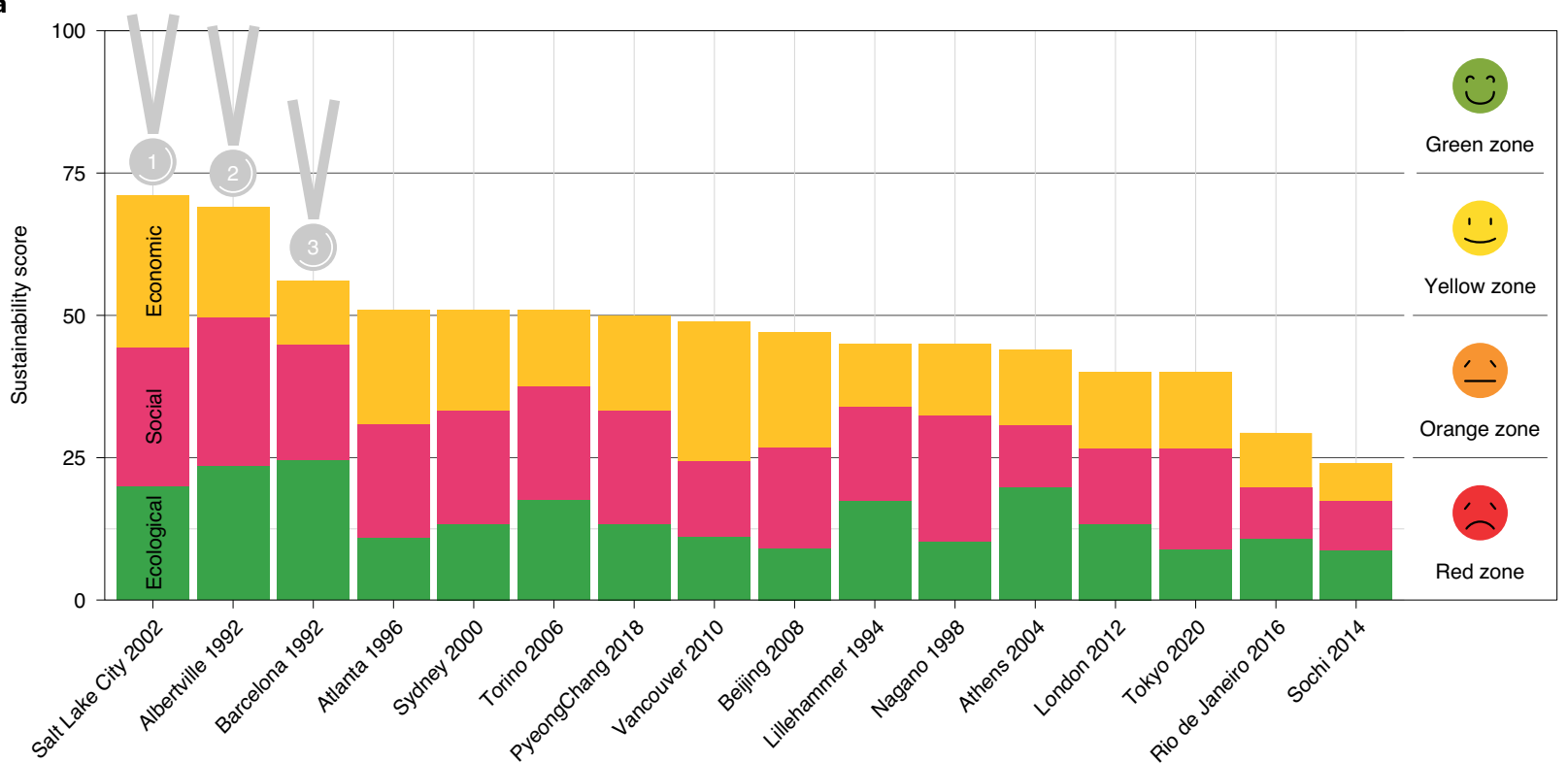

b

Albertville 1992

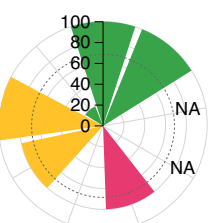

Sydney 2000

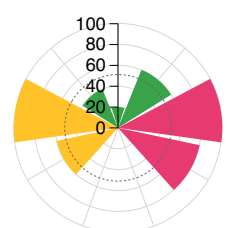

Vancouver 2010

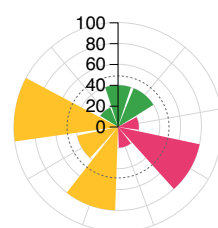

Rio de Janeiro 2016

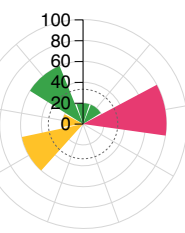

Barcelona 1992

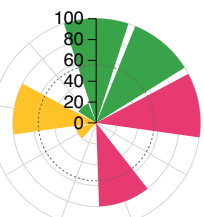

Salt Lake City 2002

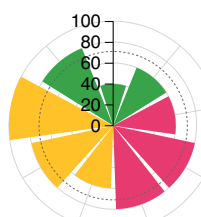

London 2012
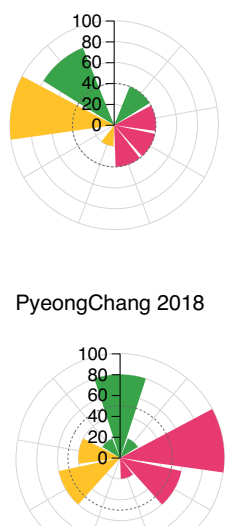

NA
Lillehammer 1994

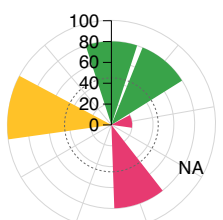

Athens 2004

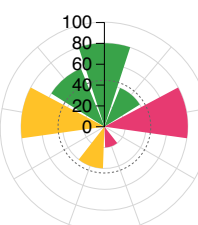

Sochi 2014
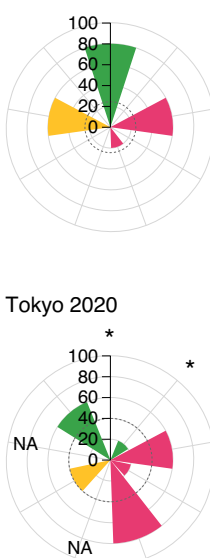

Atlanta 1996

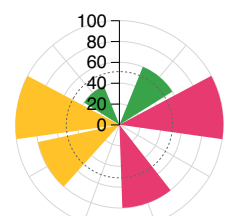

Torino 2006

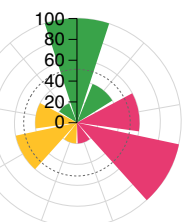

Nagano 1998

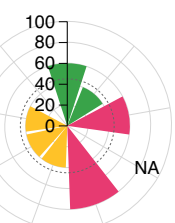

Beijing 2008

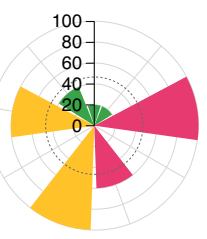

Legend

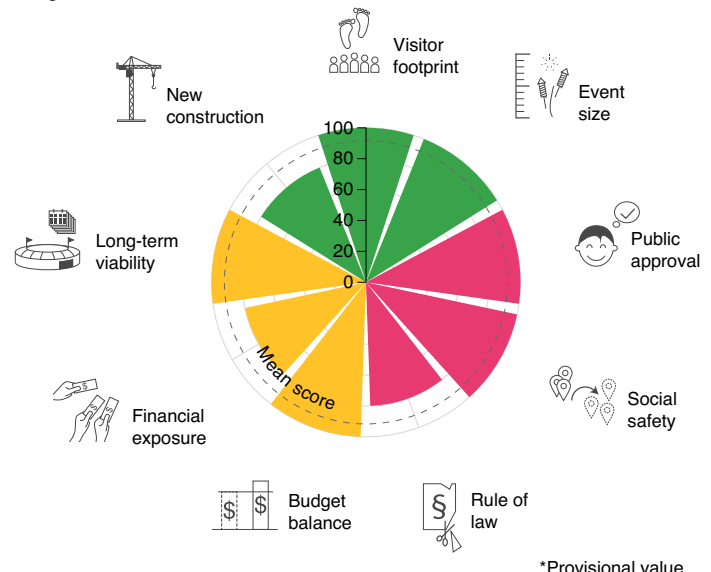

Fig. 5 | Sustainability of individual Olympic Games compared, 1992-2020. a, Ranking according to total scores. b, Individual scores. Salt Lake City 2002, Albertville 1992 and Barcelona 1992 were the most sustainable Olympic Games since 1992. Yet all three still score in the yellow zone. None of the Olympic Games since 1992 has scored in the green zone. Vancouver 2010 and London 2012 praised their own sustainability achievements but do not score at the top. The legend at the bottom right shows the maximum scores achieved on each indicator. NA, not available. 
sample that have scored highly on individual, if not on all, indicators. This result questions sceptics' claim that mega-events can never be sustainable. Yet incisive reforms are required to up the game in Olympic sustainability before these events can inspire and influence sustainable futures. These reforms need to aim both at reducing resource input and at improving the governance of the Olympic Games to produce sustainable outcomes.

The following three actions are feasible in the short run and would result in major improvements in sustainability. First, greatly downsize the event. This will lead to a gain on almost all sustainability indicators by reducing resource requirements. It will diminish the carbon emissions by visitors and bring down the ecological and material footprint by reducing the size and cost of the new infrastructure required. This measure also makes cost overruns and displacement of people less likely. Reducing in-person presence of spectators can be compensated by providing immersive sports content in digital form. Second, rotate the Olympics among the same cities. This way, all required infrastructure will already be in place, and the Olympic Games could be hosted with minimal social and ecological disruption and at minimal cost. Third and last, improve sustainability governance. This means creating or mandating an independent body to develop, monitor and enforce credible sustainability standards. This action will improve the current situation, where each Olympic host city sets its own sustainability goals and remains unaccountable when not achieving them ${ }^{15}$.

There is currently strong resistance among Olympic stakeholders to such reforms as these could jeopardize revenue flows (in the case of downsizing), reduce the universal appeal of the Olympics (in the case of rotation) and impose stringent, non-negotiable commitments to sustainability (in the case of improved sustainability governance). Until such actions are taken, however, cities and countries should rather spend public money on other measures to achieve sustainability, not on the Olympic Games.

\section{Methods}

Conceptual model. Our analysis provides an evaluation of sustainability, which is a judgement on the degree of (un)sustainability, based on ex post data on the outcomes of the Olympic Games. We took our definition of sustainable mega-events (see the preceding) as the starting point for developing the conceptual model in Fig. 1 to evaluate the sustainability of the Olympic Games. The model started from current debates on global sustainability that posit the need to respect planetary biophysical boundaries while guaranteeing a minimum threshold of social well-being ${ }^{46,47}$. It therefore measures resource consumption, such as ecological and material footprints ${ }^{48,49}$; social protection and well-being, such as social equity and social peace; and economic efficiency, such as cost overruns and long-term use of event facilities.

The model features three indicators for each of the three dimensions of sustainability (ecological, social and economic). The use of three indicators per dimension increases reliability, reducing the effect of uncertainty and measurement errors. All indicators reflect ex post data, except for Tokyo 2020, where we used the most recent estimates available by October 2020. Using ex post data corrects for the overwhelming dominance and political preference for ex ante predictions that may help to justify holding the Olympic Games vis-à-vis stakeholders but whose predictions are often wrong ${ }^{28}$. The model contains both qualitative (text-based) indicators (rule of law, long-term viability) and quantitative indicators (all others), to allow a comprehensive assessment ${ }^{50}$.

The total of nine indicators were required to fulfil two basic criteria: they needed to be valid for evaluating the sustainability of the Olympic Games and data needed to be available ${ }^{28}$. We undertook two steps to ensure the validity of the model. In a first step, we ascertained content validity by determining whether each of the nine indicators represented a major aspect both of the concept of sustainability as such and of the impacts of mega-events on sustainability. We did this through reviewing the existing literature ${ }^{24,33,51}$, and results are shown in Supplementary Table 1 in the columns 'justification' and 'relation to the literature'. We go beyond existing approaches to event sustainability by focusing not just on the presence of sustainability policies and programmes but on outcomes ${ }^{52}$ and by focusing not so much on the management practices of the event itself ${ }^{27,53}$ as on the wider impacts in the city and region.

In a second step, we ascertained attribution validity, determining whether the outcomes in the values of each indicator could plausibly be attributed to the Olympic Games. This problem of attribution is an important one when attempting to evaluate any policy or intervention, not just the Olympic Games ${ }^{24,54}$. In choosing our indicators, we opted for a plausibility approach ${ }^{54}$, meaning that we aimed to minimize the influence of confounding factors on the measured indicators to isolate, to the greatest degree possible, the impact of the Olympic Games (see column 'plausibility of attribution' in Supplementary Table 1). For this reason, we did not include indicators such as change in GDP, tourist arrivals, external image perception, air quality or others, as a plausible attribution of a change in these to the Olympic Games is difficult to establish.

It is important to note that there can never be absolute certainty that the observed change in the indicators is due to the Olympic Games. This limitation is shared among all evaluations of social phenomena against an external intervention, from public health interventions to policy evaluations, and should not preclude us from conducting such evaluations as long as we can demonstrate, as we do here, reasonable plausibility in the attribution of outcomes.

A comparative longitudinal assessment depends on the data availability of the least-well-documented event, which constrains the choice of indicators. While some Olympic Games are extensively documented (such as those of Vancouver and London, notably through the Olympic Games Impact Studies ${ }^{24,55}$ ), others, in particular older ones, are less so. As is the case with all evaluation designs, notably with those of complex phenomena such as the Olympic Games, we needed to strike a compromise between comprehensiveness and feasibility ${ }^{54}$. We should therefore stress that while we present the most comprehensive longitudinal evaluation of the sustainability of the Olympic Games to date, this is just one possible evaluation and other conceptual models are possible.

Sample delimitation. Our sample contains all Olympic Games from 1992 to 2020 $(\mathrm{N}=16)$. We have chosen 1992 as a cut-off point for five reasons. First, this is when issues of environment and sustainability started to gain traction, both globally (Earth Summit 1992) and in the Olympic Games ${ }^{56}$. Second, this is the beginning of the period when the Olympic Games began to grow considerably, with the explosion of revenues from sponsorship and broadcasting ${ }^{36}$, and therefore started to have larger impacts on their hosts. Third, from the Barcelona 1992 Olympics onwards, host cities also explicitly started to harness the Olympic Games for urban development, trying to leverage it for urban change ${ }^{57}$. Fourth, 1992 marks the point when the mega-event became a global phenomenon sensu stricto, with the integration of the former Eastern bloc into global capitalism. Fifth and last, 1992 is also a breaking point in data availability. Olympic Games before that year are less well documented, and it proved difficult to populate data points for our model.

Data collection. Data collection presented a major effort, as mega-events are known for being opaque ${ }^{3,50}$. The absence of coherent data to evaluate any aspect of the Olympic Games, not just their sustainability, is problematic, all the more so considering the exorbitant public expenditure. Part of this opaqueness results from the absence of systematic data collection across events, except for a small number of indicators by the IOC. The IOC's Olympic Games Impact (OGI) initiative-a series of independent reports before and after the Olympic Games based on indicator sets-sought to change that, with a view to comprehensively measuring the outcomes of the Olympic Games and creating a standard for sustainability across Olympic host cities $^{50}$. Launched in 2000, OGI featured a series of 126 indicators in the three spheres of economic, environmental and sociocultural impacts that are monitored over a period of 12 years. The IOC required that host cities mandate an independent research partner to carry out the study according to a set of predefined instructions ${ }^{24}$. The full cycle of four reports, however, was only completed for a single Olympic Games, Vancouver 2010. Host cities complained that the OGI was too cumbersome, so the IOC reduced the number of reports and eventually abandoned OGI altogether in January 2017, replacing it with a series of sustainability reports issued by the Olympic organizing committees ${ }^{28,58}$. This has removed the only independent, systematic data source for assessing sustainability in the Olympic Games and put in its place anecdotal reports that are issued by the very organization that is under review, thus creating a conflict of interest.

Another element of the opaqueness results from carelessness, obfuscation and sometimes deliberate destruction of records. Thus, in the run-up to the Sochi Olympic Games, accounts were sometimes not kept when under time pressure. Said one investor: "we were in such a hurry in the end that we didn't count the money" ${ }^{59}$. In many cases, crucial information is not collected, not reported, not reported transparently or not accessible to the public or to researchers. For the Nagano 1998 Olympics, hosts even deliberately destroyed part of the financial records ${ }^{60}$.

Due to this opaqueness, we were able to source only three of the nine indicators from single data sources: data for 'visitor footprint' and 'event size' could be collected from official reports of the Olympic Games, while data for 'budget balance' were sourced from a separate study ${ }^{3}$. For the remaining six indicators, we used a mixture of the following sources: bid books and official reports from the Olympic Games, independent third-party assessments (such as national audit chambers), academic literature, media reports and reports by non-governmental organizations. Many of these sources were available online for more recent events and available in archives for older events. Standardized definitions for each indicator ensured commensurability of data from different sources. For each data point, we also assessed the reliability of the source, including only data points with at least medium-high reliability in the analysis. 
While we collected data among the author team for eight editions of the event, we contracted experts to collect data and sources for another eight editions (Barcelona, Lillehammer, Atlanta, Nagano, Salt Lake City, Athens, Beijing and Vancouver). This was necessary because we either lacked the skills to read documents in the local language or needed to access archives in situ. All contractors were academics, and most of them had done previous work on the specific mega-event we commissioned them to work on. They were given a strict set of instructions and definitions to follow and were required to provide a scan of the original source for each data point. The project team validated all data points and cross-checked them against each source to ensure reliability.

Data scoring. We scored each indicator on a scale from 0 to 100 in increments of 20, where 0 means least sustainable and 100 means most sustainable. Rules for assigning scores are detailed in Supplementary Table 1. We chose end points of scores either according to natural limits (for example, in the indicator 'new construction' a score of 100 was assigned where there was no new construction) or, where these were not evident, by choosing the most extreme case in the sample. Increments between the extreme points were then defined in such a way as to create intervals of roughly equal size. To adjust for size differences between the Summer and the Winter Olympic Games, we applied different scales for these two sub-groups for two indicators ('visitor footprint' and 'event size') according to the same scoring rules (Supplementary Table 1).

The presence of values at both extremes of the scoring scale (Fig. 2b) indicates that our scoring rules are fair in the sense of not being too strict (thus making it unlikely to obtain scores of 100) or too lenient (making it easy to obtain high values).

Whereas scoring of numeric indicators was straightforward, for the two qualitative indicators, three scorers assigned scores independently from each other to increase reliability. They then discussed and resolved any differences in their scores. Out of 144 data points, 7 (4.9\%) are missing. There is no reason to assume a systematic pattern in missing values that would bias results. Missing values were therefore ignored for calculating mean scores and mean differences between groups.

For evaluating the overall sustainability of an Olympic Games, we used a score-card approach ${ }^{24}$, where we calculated the mean across all nine indicators, assigning equal weight to each score. This is a measure of relative sustainability: a score of 100 does not mean, therefore, that an event is sustainable in the sense of respecting planetary boundaries while guaranteeing social well-being ${ }^{46}$. The choice of adding scores instead of multiplying them assumes that a compensation is possible between the different dimensions of sustainability, that is, that a deficiency in one score can be compensated by a surplus in another ${ }^{55}$.

Data analysis. The sample of 16 editions makes this a set of indicators on the Olympic Games that can be analysed with inferential statistics. The sample size allows performing statistical tests with sufficient statistical power $(\pi>0.8)$ for large effect sizes $(>0.8)$ at a probability level of $0.05^{61}$. It does not, however, provide sufficient statistical power to detect medium or small effect sizes.

We checked bivariate correlations among the nine indicators (reported in Supplementary Table 2) to rule out strong correlations $(r>0.8)$, which could question the unique conceptual contribution of specific indicators. No strong correlations were found, and only 3 of the 36 correlations are significant.

We used descriptive statistics (frequencies, mean values and standard deviations) to characterize the dataset and inferential statistics (two-tailed independent samples $t$ test of mean value differences) to identify significant differences between groups. Mean scores were rounded to the next nearest integer for presentation in the manuscript. We used correlation models with Pearson's $r$ as a standardized correlation coefficient for estimating the linear trends of sustainability in Fig. 3 at a significance level of 0.05 (two-tailed).

We also constructed an exploratory regression model to examine whether we could predict sustainability scores with host context indicators ${ }^{24}$, such as the level of income in a country, the degree of corruption or the size of the host city. We did not find any significant effects (which might simply be due to a lack of statistical power, see the preceding) and therefore do not report results here.

Limitations. There is no accepted definition of the sustainability of large events. Despite justification of our choice of indicators, our model is just one model of sustainability. It is a systematic and evidence-based model, but, like all models of sustainability, it still reflects a subjective judgement about what to include in defining sustainability. Other models are possible and might result in different outcomes. The same caveat applies to the scoring, where other cut-offs and intervals are possible (which would, however, not affect the relative ranking of hosts, as the underlying data remain the same).

We also did not include potential catalyst effects of the Olympic Games on sustainability due to the absence of reliable and comparable data and to difficulties of plausible attribution. Effects typically claimed include long-term image and growth benefits, inspiring people to take up sport, lead a healthier lifestyle or become more conscious of the environment, or creating peace and intercultural understanding. In general, however, evidence is thin for claims that seek to attribute to sports the role of a larger force for bringing about social, economic and ecological benefits ${ }^{62-64}$.

\section{Data availability}

The dataset and statistical analysis are available in the mega-event dataverse on Harvard dataverse at https://doi.org/10.7910/DVN/ZARR6A.

Received: 26 March 2020; Accepted: 16 February 2021; Published online: 19 April 2021

\section{References}

1. Olympic Marketing Fact File (IOC, 2019).

2. Wade, S. \& Yamaguchi, M. Tokyo Olympics say costs $\$ 12.6 \mathrm{~B}$; audit report says much more. AP NEWS (20 December 2019); https://apnews.com/ eb6d9e318b4b95f7e53cd1b617dce123

3. Flyvbjerg, B., Budzier, A. \& Lunn, D. Regression to the tail: why the Olympics blow up. Environ. Plan. A https://doi.org/10.1177/0308518X20958724 (2020).

4. Müller, M. The mega-event syndrome: why so much goes wrong in megaevent planning and what to do about it. J. Am. Plann. Assoc. 81, 6-17 (2015).

5. Sachs, J. D. et al. Six transformations to achieve the Sustainable Development Goals. Nat. Sustain. 2, 805-814 (2019).

6. Roy, A. \& Deshmukh, R. Events Industry Market: Opportunities and Forecast, 2019-2026 (Allied Market Research, 2020).

7. Poynter, G., Viehoff, V. \& Li, Y. (eds) The London Olympics and Urban Development: The Mega-Event City (Routledge, 2015).

8. Viehoff, V. \& Poynter, G. Mega-Event Cities: Urban Legacies of Global Sports Events (Routledge, 2016).

9. Kraas, F. et al. Humanity on the Move: Unlocking the Transformative Power of Cities (German Advisory Council on Global Change, 2016)

10. van Vliet, J. Direct and indirect loss of natural area from urban expansion. Nat. Sustain. 2, 755-763 (2019).

11. Hayes, G. \& Horne, J. Sustainable development, shock and awe? London 2012 and civil society. Sociology 45, 749-764 (2011).

12. Gaffney, C. Between discourse and reality: the un-sustainability of mega-event planning. Sustainability 5, 3926-3940 (2013).

13. Boykoff, J. \& Mascarenhas, G. The olympics, sustainability, and greenwashing: the Rio 2016 summer games. Capital. Nat. Social. 27, 1-11 (2016).

14. Hall, C. M. Sustainable mega-events: beyond the myth of balanced approaches to mega-event sustainability. Event Manag. 16, 119-131 (2012).

15. Geeraert, A. \& Gauthier, R. Out-of-control Olympics: why the IOC is unable to ensure an environmentally sustainable Olympic Games. J. Environ. Policy Plan. 20, 16-30 (2018).

16. Liang, Y.-W., Wang, C.-H., Tsaur, S.-H., Yen, C.-H. \& Tu, J.-H. Mega-event and urban sustainable development. Int. J. Event Festiv. Manag. 7, 152-171 (2016).

17. Meza Talavera, A., Al-Ghamdi, S. G. \& Koç, M. Sustainability in mega-events: beyond Qatar 2022. Sustainability 11, 6407 (2019).

18. Mol, A. P. J. \& Zhang, L. in Olympic Games, Mega-Events and Civil Societies: Globalization, Environment, Resistance (eds Hayes, G. \& Karamichas, J.) 126-150 (Palgrave, 2012); https://doi.org/10.1057/9780230359185 7

19. O'Brien, D. \& Chalip, L. in Tourism Management: Analysis, Behaviour and Strategy (eds Woodside, A. G. \& Martin, D.) 318-338 (CABI, 2008).

20. Olympic Agenda 2020+5 (IOC, 2021).

21. IOC Sustainability Strategy (IOC, 2017).

22. Sport as an Enabler of Sustainable Development (United Nations General Assembly, 2018).

23. UN and Tokyo 2020, leverage power of Olympic Games in global sustainable development race. UN News (14 November 2018); https://news.un.org/en/ story/2018/11/1025711

24. Vanwynsberghe, R. The Olympic Games Impact (OGI) study for the 2010 Winter Olympic Games: strategies for evaluating sport mega-events' contribution to sustainability. Int. J. Sport Policy Polit. 7, 1-18 (2015).

25. Müller, M. et al. Dataset: Sustainability of the Olympic Games (Harvard Dataverse, 2021); https://doi.org/10.7910/DVN/ZARR6A

26. Houlihan, B., Bloyce, D. \& Smith, A. Developing the research agenda in sport policy. Int. J. Sport Policy Polit. 1, 1-12 (2009).

27. Zifkos, G. Sustainability everywhere: problematising the 'sustainable festival' phenomenon. Tour. Plan. Dev. 12, 6-19 (2015).

28. Chappelet, J.-L. Beyond legacy: assessing Olympic Games performance. J. Glob. Sport Manag. 4, 236-256 (2019).

29. O’Neill, D. W., Fanning, A. L., Lamb, W. F. \& Steinberger, J. K. A good life for all within planetary boundaries. Nat. Sustain. 1, 88-95 (2018).

30. Neumayer, E. Weak Versus Strong Sustainability: Exploring the Limits of Two Opposing Paradigms (Edward Elgar, 2003).

31. 2030 Agenda for Sustainable Development (United Nations General Assembly, 2015)

32. Adoption of the Paris Agreement FCCC/CP/2015/L.9/Rev.1 (UNFCCC, 2015)

33. Getz, D. Developing a framework for sustainable event cities. Event Manag. 21, 575-591 (2017).

34. Smith, A. Theorising the relationship between major sport events and social sustainability. J. Sport Tour. 14, 109-120 (2009). 
35. Minnaert, L. An Olympic legacy for all? The non-infrastructural outcomes of the Olympic Games for socially excluded groups (Atlanta 1996-Beijing 2008). Tour. Manag. 33, 361-370 (2012).

36. Horne, J. \& Whannel, G. Understanding the Olympics (Routledge, 2016).

37. Smith, A. Events and Urban Regeneration: The Strategic Use of Events to Revitalise Cities (Routledge, 2012).

38. Panagiotopoulou, R. The legacies of the Athens 2004 Olympic Games: a bitter-sweet burden. Contemp. Soc. Sci. 9, 173-195 (2014)

39. Searle, G. Uncertain legacy: Sydney's Olympic stadiums. Eur. Plan. Stud. 10 845-860 (2002).

40. Gold, J. R. \& Gold, M. M. 'Bring it under the legacy umbrella': Olympic host cities and the changing fortunes of the sustainability agenda. Sustainability $\mathbf{5}$, 3526-3542 (2013).

41. Holden, M., MacKenzie, J. \& VanWynsberghe, R. Vancouver's promise of the world's first sustainable Olympic Games. Environ. Plan. C 26, 882-905 (2008).

42. Andranovich, G., Burbank, M. J. \& Heying, C. H. Olympic cities: lessons learned from mega-event politics. J. Urban Aff. 23, 113-131 (2001).

43. Chappelet, J.-L. Olympic environmental concerns as a legacy of the Winter Games. Int. J. Hist. Sport 25, 1884-1902 (2008).

44. Moore, S., Raco, M. \& Clifford, B. The 2012 Olympic learning legacy agenda - the intentionalities of mobility for a new London model. Urban Geogr. 39, 214-235 (2018).

45. Temenos, C. \& McCann, E. The local politics of policy mobility: learning, persuasion, and the production of a municipal sustainability fix. Environ. Plan. A 44, 1389-1406 (2012).

46. Steffen, W. et al. Planetary boundaries: guiding human development on a changing planet. Science 347, 1259855 (2015).

47. Raworth, K. Doughnut Economics: Seven Ways to Think Like a 21st-Century Economist (Random House, 2018).

48. Borucke, M. et al. Accounting for demand and supply of the biosphere's regenerative capacity: the National Footprint Accounts' underlying methodology and framework. Ecol. Indic. 24, 518-533 (2013).

49. Wiedmann, T. O. et al. The material footprint of nations. Proc. Natl Acad. Sci USA 112, 6271-6276 (2015).

50. Leonardsen, D. Planning of mega events: experiences and lessons. Plan. Theory Pract. 8, 11-30 (2007).

51. Scrucca, F., Severi, C., Galvan, N. \& Brunori, A. A new method to assess the sustainability performance of events: application to the 2014 World Orienteering Championship. Environ. Impact Assess. Rev. 56, 1-11 (2016).

52. Laing, J. \& Frost, W. How green was my festival: exploring challenges and opportunities associated with staging green events. Int. J. Hosp. Manag. 29, 261-267 (2010).

53. Holmes, K., Hughes, M., Mair, J. \& Carlsen, J. Events and Sustainability (Routledge, 2015).

54. Habicht, J. P., Victora, C. G. \& Vaughan, J. P. Evaluation designs for adequacy, plausibility and probability of public health programme performance and impact. Int. J. Epidemiol. 28, 10-18 (1999).

55. Olympic Games Impact Study-London 2012 Post-Games Report (Univ. East London, 2015)
56. Cantelon, H. \& Letters, M. The making of the IOC environmental policy as the third dimension of the Olympic movement. Int. Rev. Sociol. Sport $\mathbf{3 5}$, 294-308 (2000).

57. Monclús, F.-J. The Barcelona model: and an original formula? From 'reconstruction' to strategic urban projects (1979-2004). Plan. Perspect. 18, 399-421 (2003).

58. Olympic Games Impact Study (Center for Olympic Studies, 2020).

59. Fedorova, M. Postolimpiyskiy sindrom. Kommersant (17 December 2014).

60. Baade, R. A. \& Matheson, V. A. Going for the gold: the economics of the Olympics. J. Econ. Perspect. 30, 201-218 (2016).

61. Tabachnick, B. G. \& Fidell, L. Using Multivariate Statistics (Pearson, 2012).

62. Coalter, F. A Wider Social Role for Sport: Who's Keeping the Score? (Routledge, 2007).

63. Billings, S. B. \& Holladay, J. S. Should cities go for the gold? The long-term impacts of hosting the Olympics. Econ. Inq. 50, 754-772 (2012).

64. Reis, A. C., Frawley, S., Hodgetts, D., Thomson, A. \& Hughes, K. Sport participation legacy and the Olympic Games: the case of Sydney 2000, London 2012, and Rio 2016. Event Manag. 21, 139-158 (2017).

\section{Acknowledgements}

We thank all who collaborated with us on the data collection. We are grateful to F. Bavaud, J. Grieshaber, J.-W. Lee, C. Guala and K. Peter for contributing to this paper in their own ways. The Swiss National Science Foundation (SNSF) funded the research of this paper under the grant Mega-events: growth and impacts, grant number PP00P1_172891.

\section{Author contributions}

M.M. designed the research, analysed the data and wrote the manuscript. M.M., S.D.W., C.G., M.H. and A.L. developed the database. M.M., S.D.W., D.G., M.H. and A.L. collected and assembled the data.

\section{Competing interests}

The authors declare no competing interests.

\section{Additional information}

Supplementary information The online version contains supplementary material available at https://doi.org/10.1038/s41893-021-00696-5.

Correspondence and requests for materials should be addressed to M.M.

Peer review information Nature Sustainability thanks Meg Holden, John Short and the other, anonymous, reviewer(s) for their contribution to the peer review of this work.

Reprints and permissions information is available at www.nature.com/reprints.

Publisher's note Springer Nature remains neutral with regard to jurisdictional claims in published maps and institutional affiliations.

(C) The Author(s), under exclusive licence to Springer Nature Limited 2021 